\title{
Crítica al discurso representativista como desenmascaramiento de la metafísica.*
}

\author{
Criticism of the representative discourse as an unmasking of the \\ metaphysics.
}

\author{
Por: Bisang, Sebastián ** \\ CONICET/CIFPE/UNC \\ Argentina. \\ Email: sebastianbisang@gmail.com \\ Fava, Fernando *** \\ UNER/UCAMI \\ Argentina.
}

Email: ferjfava@hotmail.com

Fecha de recepción: 28/08/2020

Fecha de aprobación: 09/09/2020

DOI: http://dx.doi.org/10.30972/nvt.1624533

\section{Resumen}

Los cuestionamientos nietzscheanos al pensamiento metafísico desde el rechazo a la concepción tradicional del lenguaje, se entienden a partir de la asimilación

\footnotetext{
* Este trabajo se inscribe en el Proyecto de Investigación: Retórica, verdad y metáfora en Friedrich Nietzsche (1869-1873) radicado en el Centro de Investigación de la Facultad de Ciencias Humanas de la UCAMI. Así mismo, se vincula con las actividades de investigación y docencia realizadas en el Centro de Investigación en filosofía política y epistemología (CIFPE) de la UNER.

* Licenciado en Filosofía por la Universidad Católica de Santa Fe. Becario doctoral CONICET del Doctorado en Filosofía de la Universidad Nacional de Córdoba. Profesor Adscripto de la catedra Problemática Filosófica Contemporánea de la Facultad de Ciencias de la Educación de la Universidad Nacional de Entre Ríos. E-mail: sebajstianbisang@gmail.com.

${ }^{*} * *$ Licenciado en Filosofía por la UNC. Dr. en Filosofía por la UCSF. Estudios de posgrado en la SEDEN (Sociedad Española de Estudios Nietzsche). Profesor Adj. ord. de la cátedra Historia de los Sistemas Filosóficos de la FCED de la UNER. Prof. Titular de la cátedra Filosofía Contemporánea de la UCAMI. Director del Centro de Investigaciones en Filosofía Política y Epistemología de la UNER. Investigador del Centro de Investigaciones de la Facultad de Ciencias Humanas de la UCAMI. E-mail ferjfava@hotmail.com
} 
Crítica al discurso representativista como desenmascaramiento de la metafísica.

crítica que Nietzsche realiza de pensadores inscriptos en la órbita del neokantismo como podrían considerarse a Schopenhauer, Hartmann o Lange.

Durante los años 1865-1872, de un modo muy intuitivo, con fórmulas heredadas de su admirado maestro Schopenhauer, y bajo el influjo del proyecto cultural wagneriano, Nietzsche va combinando su bagaje cultural con lecturas de pensadores de cuño crítico como Lange o Hartmann. Ensayando su propio pensamiento desde bocetos no exentos de tensiones y confrontaciones, como también de intuiciones geniales. Un universo de lecturas que poco tiempo después (1873) el joven catedrático de Basilea, reorientará desde los aspectos tropológicos del lenguaje, a partir de su recepción de Die Sprache als Kunst de G. Gerber.

En el siguiente artículo, nos proponemos trazar una génesis de su crítica al "pensamiento metafísico" desde la reconstrucción de sus preocupaciones tempranas en torno al conocimiento. Focalizándonos en los Nachgelassene Fragmente de este período (1865-1875), intentaremos reconstruir la poliédrica recepción nietzscheana de la crítica epistemológica asumida por Lange, el valor de lo instintivo-inconsciente en la configuración de las representaciones sostenida por Hartmann y el carácter ilusorio del conocimiento propuesto por Schopenhauer. Un entramado de ideas que bien reflejan los póstumos de esta etapa y que, si tomamos como hilo genealógico-interpretativo sus preocupaciones lingüísticas, se revelarán como la verdadera geología del mapa conceptual explayado en Über Wahrheit und Lüge im aussermoralischen Sinne. Escrito en el que Nietzsche no sólo sintetiza, concretiza y clarifica este camino de búsqueda, sino que prefigura los parámetros, la cartografía, de su pensamiento maduro.

Palabras clave: Nietzsche, verdad, conocimiento, fisiología, ilusión.

\section{Abstract}

The Nietzschean questions to metaphysical thought from the rejection of the traditional conception of language, are understood from the critical assimilation that Nietzsche makes of thinkers enrolled in the orbit of neo-Kantianism as Schopenhauer, Hartmann or Lange. 
During the years $1865-1872$, in a very intuitive way, with formulas inherited from his admired teacher Schopenhauer, and under the influence of the Wagnerian cultural project, Nietzsche combines his cultural background with readings of critical thinkers such as Lange or Hartmann. Rehearsing his own thinking from sketches that are not without tension and confrontations, as well as great insights. A universe of readings that a short time later (1873) the young professor from Basel, reoriented from the tropological aspects of language, from his reception of Die Sprache als Kunst by G. Gerber.

In the following article, we propose to trace a genesis of his critique of "metaphysical thought" from the reconstruction of his early concerns about knowledge. Focusing on the Nachgelassene Fragmente of this period (1865-1875), we will try to reconstruct the multifaceted Nietzschean reception of the epistemological critique assumed by Lange, the value of the instinctual-unconscious in the configuration of representations sustained by Hartmann and the illusory character of knowledge proposed by Schopenhauer. A network of ideas that well reflect the posthumous fragments of this stage and that, if we take their linguistic concerns as a genealogical-interpretative thread, will reveal themselves as the true geology of the conceptual map expanded in Über Wahrheit und Lüge im aussermoralischen Sinne. Work in which Nietzsche not only synthesizes, concretizes and clarifies this path of search, but prefigures the parameters, the cartography, of his mature thought.

Keywords: Nietzsche, truth, knowledge, physiology, illusion.

\section{Cómo citar este artículo:}

APA: Bisang, S. y Fava F. (2020). Crítica al discurso representativista como desenmascaramiento de la metafísica. Nuevo Itinerario, 16 (2), 27-51. Recuperado de: (agregar dirección web) 
Crítica al discurso representativista como desenmascaramiento de la metafísica.

\section{Introducción a la perspectiva crítico-fisiológica}

Es durante el primer mes de estancia como estudiante de filología en Leipzing (Octubre-Noviembre de 1865) cuando Nietzsche realiza su primera lectura de Die Welt als Wille und Vorstellung ${ }^{1}$. Una lectura febril y apasionada que, si bien desemboca en una adhesión incondicional a las tesis schopenhaurianas como eco de sus más profundos cuestionamientos existenciarios, lo incentiva, a la vez, a profundizar en la lectura filosófica, a ir más allá de su formación filológica; a confrontarla y confrontarse con el amplio abanico que empezaba a descubrir en la filosofía.

Dicha inquietud intelectual lo lleva a conocer en el verano de 1866, inmediatamente después de su publicación, la Geschichte des Materialismus ${ }^{2}$ de F. Lange, texto que jugará un papel preponderante en la emancipación de Nietzsche frente a la filosofía dogmática como del propio paradigma shopenhauriano.

Esta breve historia de la filosofía lo pone en contacto con las perspectivas naturalistas, positivistas del momento. En la dirección del neokantismo.

Por otra parte, el materialismo (según lo sostiene el mismo Lange) no puede explicar la actividad de la conciencia como realidad organizadora y categorizadora. Una insuficiencia que es superada solamente cuando se adopta la teoría kantiana del conocimiento desde una interpretación psicológica, y hasta psicofisiológica, del sujeto trascendental. Las categorías son así entendidas como formas del sujeto real y no condiciones puras de la posibilidad del conocimiento. Rechazando consecuentemente tanto el valor científico de la metafísica, a la cual estima como "poesía conceptual".

En este sentido, Curt Janz, el biógrafo de Nietzsche, ha destacado en tal sentido que:

\footnotetext{
${ }^{1}$ Sobre las circunstancias del hallazgo de la obra y las reacciones que le suscita, consultar Curt (1981). Así como la atmósfera de descubrimiento óptimamente reconstruida por Safranski (2001) y la cálida biografía de Halévy (1943)

2 Lange, Friedrich Albert, Geschichte des Materialismus und Kritik seiner Bedeutung in der Gegenwart, Iserlohn, 1866. Nosotros citamos de la Edición en 2 Vol. de la Suhrkamp Verlag, Frankfurt am Main, 1974, con las siglas $G d M$, seguidas de la indicación de volumen en número romano y de la página correspondiente en arábigo. Adviértase las primeras referencias a la lectura de esta obra en las cartas a sus amigos Carl von Gesdorff y Hermann Mushacke (agosto y noviembre de 1866) "La obra filosófica más importante que ha aparecido en el último decenio, es sin duda, la de Lange, Historia del materialismo, sobre la que podría escribir un discurso laudatorio de un montón de páginas. Kant, Schopenhauer y este libro de Lange, no necesito más". (KSB 2, pp. 159-161 y 184) Siendo en esta última donde mejor podemos observar la impresión inicial que el libro le causó.
} 
Lange traza una línea de demarcación abrupta y de principio entre el conocimiento empírico en cuanto verdad científica y todo tipo de metafísica como poesía conceptual, y rechaza a la vez cualquier posible identificación entre ser y pensamiento del tipo de las ensayadas por Platón o Hegel. Este talante crítico-epistemológico de Lange vino a reforzar una convicción latente ya de modo muy profundo en el joven Nietzsche, a saber, que la vida y el mundo son, por su naturaleza misma, a-lógicos y se resisten a todo intento de ser captados y dominados por la vía del entendimiento puro (Curt,1981, p.174).

Esta perspectiva crítico-epistemológica de Lange ${ }^{3}$ afianza al joven Nietzsche en su rechazo a cualquier posible identificación entre ser y pensamiento, e incentiva y orienta su desarrollo intelectual (entre finales de 1867 y enero de 1868) hacia la obra de Kant desde la lectura de los dos tomos de Kuno Fischer sobre el estudio de la Kritik der Urteilskraft. Período en el que empieza a cuestionar las lagunas del corpus schopenhauriano, pero que irá menguando hacia finales de 1869 cuando conoce a R. Wagner a cuya música y proyecto cultural adhiere completamente. Será en 1872, cuando la evolución intelectual del joven Nietzsche manifieste una inflexión al ocuparse nuevamente de la cuestión de la cosa en sí desde una incipiente metafísica de artista, que preocupada por el lenguaje, se irá paulatinamente respondiendo y desmarcando tanto de la filosofía denominada por Kant como dogmática, como del mismo espacio crítico inaugurado por este y su recepción o re-interpretación por parte de Schopenhauer.

Durante los años previos a su ingreso como profesor en Basilea tanto la Geschichte des Materialismus de Lange, como Die Welt als Wille und Vorstellung de Schopenhauer, constituyen las experiencias filosóficas fundamentales que orientan su búsqueda de un lenguaje propio. Dichos textos serán el privilegiado material preparatorio para la tesis doctoral -que no llegaría a concluirse- Begriff des Organischen seit Kant, en cuyo centro se coloca la preocupación por la teleología

\footnotetext{
${ }^{3}$ Sobre la relación Lange- Nietzsche seguimos los lineamientos interpretativos establecidos desde el estudio comparado de los textos que ha realizado Sánchez, S. (1999) el cual asume y a la vez nos remite a los importantes trabajos de Salaquarda, J. (1979), Campioni, G., ,Venturelli, A. (1992) y Stack, G. (1983). Así mismo, señalamos el excelente y sintético planteamiento de las diversas líneas de investigación que el estudio de dicha relación ha realizado Barrios Casares, M. (2002)
} 
Crítica al discurso representativista como desenmascaramiento de la metafísica.

en el deseo de establecer una clara determinación de los límites del conocimiento ${ }^{4}$.

La recepción y posterior radicalización nietzscheana del criticismo kantiano, como interpreta Jesús Conill, consistirá:

en transformar la crítica de la razón pura en una crítica de la razón impura, es decir, en descubrir que en la razón humana no hay sólo elementos lógicos, sino también corporales, lingüísticos, perspectivos y afectivos, que no son "lo otro" de la razón, sino componentes de la razón. Nietzsche amplía el criticismo kantiano, eminentemente lógico, mediante un criticismo fisiológico, lingüístico, mediante la crítica de la verdad y el descubrimiento del carácter vital perspectivita de la razón (Conill, 1997, p.26).

Este paso del ámbito lógico-formal al de una concepción del conocimiento que, acaeciendo como arte interpretativo, comienza a gestar el nuevo criticismo nietzscheano desde una insipiente radicalización fisiológica de la crítica trascendental kantiana, se basa en interpretar a Kant y Schopenhauer desde el modelo proporcionado por Lange.

Si bien el primer encuentro con el criticismo fue Schopenhauer ${ }^{5}$; el acceso a Lange le permitirá criticar no sólo los fundamentos de la filosofía tradicional, o el espacio inaugurado por Kant, sino también, y de un modo no exento de ambigüedades, las enseñanzas de su reciente y admirado maestro Schopenhauer.

Nietzsche comienza interpretando la tesis langeana sobre la irreductibilidad de lo real a los elementos puramente lógicos y racionales, como una apología del sistema de Schopenhauer.

Nietzsche supone inicialmente esta cercanía a los principios neokantianos de Lange porque Schopenhauer, aún en un sentido radicalmente distinto del de Kant, sostiene la incapacidad de la razón humana para conocer la verdadera esencia de las cosas. En este punto, pues, todavía resulta posible mantener la afinidad entre ambas concepciones. Ahora bien, mientras que a partir de ahí Lange siguiendo los principios kantianos insiste en la imposibilidad absoluta de conocer el en sí de la realidad, por el

\footnotetext{
${ }^{4}$ Para un mayor desarrollo de la problemática ver: Gentilli, C. (2010)

${ }^{5}$ La relación de Nietzsche con el criticismo kantiano, en primera instancia dependiente de Schopenhauer, será inmediatamente ampliado al enfoque de Lange permitiéndole el inicio de un camino propio y auténtico.
} 
contrario, Schopenhauer propone una vía alternativa a la horizontal-representativa, abriendo una puerta de acceso a lo indeterminado desde la dirección vertical que proporciona un vehículo no racional como es el del arte. En una carta a su amigo Gesdorff, el joven Nietzsche comparte sus preocupaciones teoréticas (críticoepsitemológias) reflejando de una manera ambigua la incorporación tanto de las tesis de Lange como las de su maestro Schopenhauer que en estos momentos estima conciliables:

1) El mundo sensible es el producto de nuestra organización.

2) Nuestros órganos visibles (corporales) son solamente, al igual que todas las otras partes del mundo fenoménico, imágenes de un objeto desconocido.

3) Por tanto, nuestra organización real permanece tan desconocida para nosotros como las cosas externas reales. Lo único que tenemos siempre ante nosotros es el producto de ambas.

Así, pues, la verdadera esencia de las cosas, la cosa en sí, no sólo nos es desconocida, sino que además su concepto no es ni más ni menos que la creación última de un objeto condicionado por nuestra organización, del que no sabemos si fuera de nuestra experiencia posee algún significado. De ahí, opina Lange, que haya que dejar a los filósofos en libertad, a sabiendas de que siempre intentarán edificarnos. El arte es libre, también en el ámbito de los conceptos. (...) Ya ves que nuestro Schopenhauer resiste incluso este punto de vista rigurosamente crítico (Nietzsche, eKGWB/BVN-1866,517) ${ }^{6}$

Como podemos observar, el texto es ambivalente, si bien por un lado se confronta, muy tempranamente, con el marco trascendental kantiano aludiendo las tesis langeanas en referencia a la organización sensible del individuo, sigue a su vez a Kant en su tesis fundamental de que "la verdadera esencia de las cosas nos es desconocida". Admitiendo por otra parte, la superioridad del arte (sostenida por Schopenhauer) en relación al concepto, pero de la cual no afirma que nos suministre un conocimiento más verdadero de lo real.

Asimismo, la referencia a la libertad del arte en relación al concepto, alude

\footnotetext{
${ }^{6}$ Las obras de Nietzsche y los fragmentos póstumos se citan de acuerdo a las siglas y las referencias utilizadas en los aparatos críticos de la edición eKGW. En esta carta a su amigo Carl von Gersdoff de fines de agosto de 1866, Nietzsche no sólo concibe como conciliable dichas tesis, sino que incluso considera que es precisamente Lange quien le ha revelado el verdadero significado que la obra de Schopenhauer tiene para él en tanto "poema conceptual". Schopenhauer resiste de este modo las críticas lógico-teoréticas que, como vemos, Nietzsche es capaz de dirigir en este período tan temprano de su pensamiento.
} 
Crítica al discurso representativista como desenmascaramiento de la metafísica.

precisamente a uno de los puntos en el que se funda para Nietzsche el valor edificante de la filosofía de Schopenhauer (y de toda filosofía) en tanto "poema conceptual de la especulación". Denominando de este modo - según lo había establecido Lange - a aquella empresa que el espíritu mismo acomete cuando pretende una interpretación del conjunto de la realidad, pero que a su vez no es entendida como una ampliación de los límites de nuestro conocimiento, sino como creación artística. Es decir, la construcción de una Weltanschauung, el afianzamiento de un determinado pathos de lo que no se puede propiamente escribir una crítica.

Cabe admitir, entonces, que estamos en el inicio de un camino que progresivamente tomará distancia de sus principales referentes y que a su vez refleja un itinerario de lecturas hasta entonces desconocidas por Nietzsche y que suponen el contacto con un criticismo metafísico más radical que el estrictamente kantiano, cual es el caso del que el joven Nietzsche encuentra reflejado en la obra de Lange ${ }^{7}$. Lecturas desde las cuales empezará a problematizar una y otra vez -desde el horizonte de la intimidad de sus reflexiones- la pretensión de Schopenhauer de hacer asequible, si bien de un modo del todo distinto al de Kant, la cosa en sí.

El término Wille, con que Schopenhauer pretende haber despejado la incógnita de la ecuación de Kant, comienza a parecerle una palabra "grosera y demasiado abarcadora" dada a luz sólo merced a una intuición poética, en tanto que los intentos de demostraciones lógicas "no pueden satisfacer ni a Schopenahuer ni a nosotros" (Nietzsche, eKGWB/BVN-1866,517). Todo cuanto Schopenhuer hace valer como cosa en sí, no es más que una suma de predicados inapropiados para "algo que es por definición impensable, demasiado determinados y tomados todos de la antítesis con el mundo de la representación, mientras que entre la cosa en sí y el fenómeno ni

\footnotetext{
${ }^{7}$ Como oportunamente lo señala Sánchez, S. (1999), el influjo de Lange perdura de manera notable y de diversos modos e importancias en la reflexión nietzscheana. Pues en dicho estímulo el joven Nietzsche encuentra un acceso privilegiado a las investigaciones científicas de su época, lo que posibilita su temprana familiaridad con las propuestas de Du Bois Raymond, Helmholtz, Zöllner, Czolbe, Fechner, Darwin, etc, ideas que tendrán una notable gravitación en la elaboración de su propia filosofía.
} 
siquiera el concepto de antítesis tiene sentido" (Nietzsche, eKGWB/BVN-1866,517). ${ }^{8}$

Si la crítica de Kant era eminentemente una crítica lógica, la de Nietzsche, se irá constituyendo a partir de su encuentro con los textos de Lange, en una crítica fisiológica. Una crítica que abandonando el mero juicio a la razón pura se adentra en la genealogía de nuestra organización psíquico-física, en la unidad de los psíquico (interior) y lo físico (exterior) como articulará Lange y que le permitirá comenzar el camino de la superación del punto de vista dogmático, de la distinción del mundo como phaenomena y noumena.

Esta defensa de la "unidad" del hombre, inspirada en Lange y en los pensadores al que éste introduce, le permite contactar con la idea de una psique fundada en una realidad física (neokantismo fisiológico), y profundizar en perspectiva, que intentando pensar "siguiendo el hilo conductor del cuerpo", ofrece una interpretación del mismo a partir de sus síntomas.

Si bien Nietzsche está moviéndose en la órbita kantiana, y como lo han expuesto intérpretes como Salaquarda (1978 pp. 236-253) -para quien la vinculación con el método crítico de orientación kantiana debe considerarse como un elemento

\footnotetext{
${ }^{8}$ La impronta de Lange se hace evidente en estas críticas en las que Nietzsche no hace otra cosa que usar contra Schopenhauer las mismas observaciones realizadas por Lange en su exposición del sistema de Kant. En efecto, al ocuparse del agnosticismo kantiano, explicitado en la afirmación de que la cosa en sí trasciende nuestro conocimiento, Lange (1974) escribe: "La verdadera esencia de las cosas, el fundamento último de todas las apariencias, no sólo es desconocido para nosotros, sino que incluso su concepto no es nada más ni nada menos que el último producto de una antítesis determinada por nuestra organización, y de la cual no sabemos si, ,más allá de nuestra experiencia, conserva algún significado" (p.499)

En este sentido Safranski (2001) expresa: "A través de Lange conoció Nietzsche la teoría del conocimiento de Kant, el materialismo antiguo y el moderno, el darvinismo y los rasgos fundamentales de las modernas ciencias naturales; en consecuencia, agudizó su atención y descubrió algunas fracturas teóricas en el sistema de Schopenhauer. No se puede, advierte, hacer ninguna afirmación acerca de la desconocida "cosa en si", y ni siguiera se puede decir que todos los predicados del mundo fenoménico, como el espacio, el tiempo y la causalidad, han de eliminarse de esta "cosa en sí". Lo inaccesible al conocimiento no puede interpretarse como imagen negativa de lo cognoscitivo, pues también con la lógica de la oposición se trasladan falsamente determinaciones del mundo cognoscitivo a lo indeterminable. La "cosa en sí" ni siquiera puede interpretarse como voluntad, pues eso lleva consigo una afirmación demasiado determinada sobre la esencia indeterminable del mundo. Ve claro que la "voluntad" es un poder elemental, e incluso el poder primario de la vida, pero critica el hecho de que se asigne a la "voluntad" aquel lugar categorial que Kant había dejado libre para la "cosa en si'”." (p. 49)
} 
Crítica al discurso representativista como desenmascaramiento de la metafísica.

primordial desde los mismos orígenes de la gestación del pensamiento nietzscheanose diferencia, a su vez, claramente de éste en que Nietzsche (a partir de la lectura de Lange) intentará superar la visión trascendental kantiana desde la referencia, a la organización humana, a la unidad psico-física del hombre, la cual, como producto de un devenir, de una evolución histórica, evidenciará el carácter interpretativo, meramente humano, de las condiciones apriorísticas del conocimiento.

Esta acentuación de las tendencias encontradas en Lange lo afianzarán en la convicción de un criticismo radical, según el cual, todo lo que podemos conocer pertenece al mundo fenoménico, incluso la facultad mediante la que conocemos (los sentidos y el cerebro). Una concepción del conocimiento que no concierne sólo a la razón, sino que (prosiguiendo lecturas de autores como Zollner, a los cuales había abierto las puertas Lange) se extiende hasta el nivel de los sentidos, a la unidad psicofísica del hombre. La sensación, lo dado inmediatamente se constituye como el hecho fundamental a partir del cual se origina las construcciones mediatas.

Como interpreta Jesús Conill:

Nietzsche prosigue el criticismo de Lange y recurre a la instancia de "nuestra organización" fisiológica para explicar la historia de las proyecciones de un "mundo verdadero" (desde Sócrates a Kant). Desde esta perspectiva criticista radicalizada, todos los productos ideales son de la misma condición que los "fenómenos", porque ha desaparecido la diferencia (por oposición) entre un mundo fenoménico y un mundo verdadero, ya que todo es interpretación. No es que haya múltiples interpretaciones de lo mismo, sino que la consecuencia última del criticismo desarrollado por Nietzsche va más allá de Kant y Lange: nuestra organización produce esquemas de interpretación (Conill, 1997, p.19).

Creemos oportuno señalar a fin de dar claridad al desarrollo de nuestro trabajo, y continuando los estudios críticos de J. Conill, que esta ubicación de Nietzsche dentro de la tradición del neokantismo de Lange, ha cimentado opiniones como la de G. Stack (1983) quien ve tanto en la concepción naturalista, como en el contexto social desde donde Nietzsche explicará el lenguaje una influencia directa de F. Lange.

Por otra parte, pensadores como R Löw (1984) siguen los lineamientos básicos de esta línea interpretativa ampliándola incluso hasta Schopenhauer, viendo la influencia directa de este último en textos donde Nietzsche se refiere al origen 
instintivo-inconsciente del lenguaje y los aportes de Lange se reflejarían en aquellos donde el lenguaje se concibe como producto del pacto social.

Desde nuestro punto de vista y siguiendo la línea interpretativa señalada por Jesús Conill y Sergio Sánchez, en su trabajos referentes a la recepción de nietzscheana del espacio crítico inaugurado a partir de Kant; y de otros intérpretes en relación a la problemática del lenguaje como Luis de Santiago Guervós, rescatamos como decisivos los aportes de Lange en la órbita del legado crítico, inclinándonos a concebir que los aportes más decisivos en relación a la concepción del lenguaje se introducirán a partir de la recepción que Nietzsche realiza de la obra de Gustav Gerber Die Sprache als Kunst y su idea del lenguaje como arte retórico.

En este sentido el ámbito de reflexión inaugurado por la perspectiva críticofisiológica del joven Nietzsche, en relación al lenguaje y el conocimiento, orienta su mirada hacia el sentido y valor de lo instintivo-inconsciente en la configuración de las representaciones. Comienza a preguntarse sobre la interacción de los niveles de consciencia e inconsciencia presentes en el hombre.

Vincular dicha problemática a lo inconsciente (Unbewusst), puede ser comprendido en el contexto de discusión iniciado por la llustración y el Romanticismo durante el siglo XVIII en torno al carácter y rol del mismo en el proceso de conocimiento. La concepción ilustrada de un inconsciente cognitivo como base de toda actividad psíquica, es refutada por el romanticismo desde la noción de un inconscientevital, a partir del cual se señala la importancia de los sentimientos y pasiones en las configuraciones cognitivas en detrimento del rol desempeñado por la razón o entendimiento (De Santiago Guervós, 2004). Durante este período Nietzsche mantendrá representaciones "románticas" del inconsciente como lo más originario y auténtico en relación al plano de la razón-conciencia. ${ }^{9}$ Un abordaje de las cuestiones referente al lenguaje que sintoniza con sus lecturas de autores como Schelling o Eduard von Hartmann.

Nietzsche comienza a valorar el plano de lo inconsciente en la configuración del conocimiento, a escrutar lo inconsciente (en el que se asienta el impulso creador

\footnotetext{
${ }^{9}$ En este sentido véase: Wegener, M. (2005, pp. 202-240) y Göde, G.( 1999)
} 
Crítica al discurso representativista como desenmascaramiento de la metafísica.

artístico) como condición de posibilidad, de la conciencia. Es decir: el lenguaje no encuentra su origen en la conciencia, sino en un nivel oscuro y profundo que la condiciona como lo más real.

El interés de Nietzsche por descubrir la razón oscura de nuestro mundo consciente está motivado, en parte, por la lectura de una obra que caminaba "por las sendas de Schopenhauer": Philosophie des Unbewussten de Eduard von Hartmann (1869) ${ }^{10}$, de la que había tomado conocimiento durante el último invierno en Leipzig.

Lo que plantea Hartmann en dicha obra es una nueva perspectiva de abordaje a la conciencia, a la razón, desde el ámbito del lenguaje como expresión del instinto (Instintikt). Sosteniendo como idea central que todo pensamiento consciente es sólo posible con la ayuda del lenguaje. Que el lenguaje es la condición de posibilidad de la consciencia y no su consecuencia.

Introduciendo lo inconsciente-instintivo como fundamento de toda actividad humana consciente, presenta el lenguaje como el fruto de una "actividad espiritual inconsciente (Unbewusst)". El origen del lenguaje, y en consecuencia el de la conciencia (Bewusstsein), hunde sus raíces en la actividad creativa de la esfera del inconsciente. Lo instintivo-inconsciente se presenta como origen último del lenguaje y del pensamiento (Hartmann, 1869).

Esta nueva perspectiva introduce un cambio de sentido significativo en las investigaciones del joven pensador alemán. Al destacar el papel condicionante del lenguaje respecto a la razón, ésta no sólo pierde su carácter autónomo, puro e inmaculado, sino que, al revelar su dependencia instintivo-lingüística, desplaza el interés de la crítica filosófica nietzscheana hacia ese otro ámbito fundamental que es la crítica del lenguaje en cuanto producto de lo inconsciente, del instinto; referencia

\footnotetext{
${ }^{10}$ Se observa una primera mención de este pensador en la carta a Gersdorff del 4 de agosto de 1869, al final de la cual recomienda vehementemente la lectura de su obra, "a pesar de la mala fe del autor". (Nietzsche, eKGWB/BVN-1869,19) Sobre la influencia de Hartmann en la filosofía de Nietzsche durante el período de Basilea, véase Gerratana,F.,(1988, pp.391-433). El cual nos conduce a su vez a los prestigiosos estudios de Claudia Crawford C. (1988) y A. Mittasch A. (1952) en referencia al lenguaje, los cuales señalan que la idea de Nietzsche en relación al inconsciente procede de Schelling, Schopenhauer y E. von Hartmann. De este modo, según lo indica Crawford (1988), la Philosophie des Unbewussten "no solamente proporcionó al joven Nietzsche algunas ideas interesantes sobre el origen del lenguaje, sino que vino llenar un gran vacío en su pensamiento sobre el lenguaje, un vacío que había sido abierto, pero no llenado satisfactoriamente, por sus lecturas de Kant y Schopenhauer".
} 
última de los valores, de nuestros juicios y, en general, de toda la actividad de nuestro entendimiento.

Para Nietzsche el instinto no es el resultado de una reflexión consciente, ni consecuencia de la organización corporal. Tampoco es producto de un mecanismo que se impone desde fuera del individuo como algo extraño al mismo. El instinto es mayor logro particular de los individuos, de las masas, salido de su carácter. El instinto y el núcleo más íntimo de un ser son una sola cosa (Nietzsche eKGWB/NF-1869, 2[3,20.22], eKGWB/GMD-1, eKGWB/ST-1, eKGWB/NF-1870, 5[75,77])

El problema del origen del lenguaje, de las representaciones, del pensamiento consciente, mantenido tradicionalmente por la filosofía en el ámbito de la conciencia, es trasladado ahora a la esfera productiva del inconsciente.

Nietzsche era ya consciente, desde su época juvenil, de que los impulsos y toda su fuerza dionisíaca expansiva son abreviados y reducidos bajo la forma de pensamiento y lenguaje. Todo muestro mundo de apariencias (la ciencia, la cultura, la filosofía) es "un símbolo del instinto". Un símbolo que se conforma desde dos lenguajes o fuerzas diferenciadas: la dionisíaca: referida a lo inconsciente-instintivo y como perteneciente "al núcleo más íntimo de su ser"; y la apolínea: vinculada a lo consciente-conceptual y configurada a través del proceso de fijación y pauperización simbólica.

El mundo de las apariencias empieza a revelarse como el producto de un proceso de simbolización. ¿Pero en qué consiste este proceso? ¿Cómo interactúan entre sí los distintos lenguajes o fuerzas que dan origen al símbolo? ¿Cuál es su relación con el mundo?

\section{El carácter simbólico de las representaciones}

El flamante profesor de Basilea comienza a ordenar los apuntes para sus primeros cursos de universidad desde el interés por desentrañar la esencia del lenguaje, como un punto o idea dinámica desde la cual podría esclarecerse su continua preocupación por el "mecanismo de la representación". Motivo por el cual su 
Crítica al discurso representativista como desenmascaramiento de la metafísica.

inclinación por asimilar los distintos modelos con que la tradición intentó explicarse el lenguaje, se traduce en un creciente interés por cuestiones como el símbolo, el arte, el instinto y la música.

Como bien lo podemos ir rastreando en los fragmentos póstumos, muy tempranamente, en otoño de 1869 y en el marco de sus investigaciones acerca del drama musical griego, Nietzsche aborda el marco general de la problemática del lenguaje, desde una previa reflexión acerca de temas como la figura de Sócrates, las pretensiones de la ciencia, o el papel del inconsciente. Reflexiones todas, que pocos meses después empezarán a acotar, y a su vez enriquecer, la problemática desde las ideas ilusorias (Wahn) griegas como medidas necesarias del instinto (Instintikt) y saludable para la vida.

Desde un pensamiento de marcada perspectiva romántica, Nietzsche plantea las primeras relaciones entre música y lenguaje desde la función de la palabra dentro del marco de la ópera. La palabra problematizada desde lo simbólico le permite una paulatina interiorización de la intuición estética en los griegos, reflexiones expresadas a partir de 1870 desde recurrentes anotaciones respecto al simbolismo del sonido, la relación lenguaje-gesto-grito y esencia de las cosas. Así, el lenguaje -la palabra como "superficie del mar agitado"- se va configurando como el simbolismo infinitamente imperfecto formado según las leyes de la naturaleza, del instinto (Nietzsche, eKGWB/NF-1869, 2[6, 2,10, 11, 14, 15, 26]). ${ }^{11}$

Entre los múltiples fragmentos de este período encontramos numerosos apuntes que expresan su preocupación gnoseológica desde el punto de vista del lenguaje: "El lenguaje, la palabra no son más que símbolos. El pensamiento, es decir, la representación consciente no es más que la actualización y la relación de los símbolos

\footnotetext{
${ }^{11}$ Creemos oportuno hacer notar que estas recurrentes anotaciones acerca de la problemática del conocimiento desde una incipiente preocupación acerca del lenguaje, tienen como marco general las reflexiones que el joven Nietzsche realiza en referencia al problema de la cultura desde sus aspectos específicos como por ej. el Estado, la división del trabajo, la educación, la esclavitud, la mujer, el pesimismo, el idealismo o la religión. Características que denotan un modo de entender la praxis filosófica, un arte combinatoria de los distintos aspectos de la vida, que nos advierte de la necesidad de una interpretación histórica-filológica de los textos.
} 
lingüísticos." (Nietzsche, eKGWB/NF-1870, 5[80]). ${ }^{12}$

El concepto, en el primer momento de su emergencia, un fenómeno artístico: la simbolización de toda una multitud de apariencias, originalmente una imagen, un jeroglífico. Así, una imagen en un lugar de una cosa... Nuestro entero mundo de la apariencia es un símbolo de los instintos... ¿Cuál es la relación del concepto con el mundo de la apariencia? Aquél es el prototipo de muchas apariencias. El signo distintivo de los mismos instintos (Nietzsche, eKGWB/NF-1870, 8[41]).

Asimismo, en el escrito Die dyonisische Weltanschauung de agosto de 1870, abordando el problema de la relación entre las representaciones conscientes y los sentidos, desde la perspectiva del lenguaje de los gestos y sonidos (como comunicación instintiva-inconsciente y de carácter simbólico) Nietzsche especifica:

Símbolo significa aquí una reproducción completamente imperfecta y fragmentaria, un signo alusivo sobre cuya comprensión hay que llegar a un acuerdo: sólo que, en este caso, la comprensión general es una comprensión instintiva, es decir que no ha pasado a través de la conciencia clara (Nietzsche, eKGWB/NF-1870, 8[41]).

En tanto es inicialmente símbolo, el concepto, la palabra, difiere de la cosa, guarda respecto de ésta la distancia y la divergencia que la mala copia mantiene con el original: en todo caso, en tanto creación ("fenómeno artístico"), introduce en el plano de la representación algo que es extraño y "exterior" a la cosa y que en lo inmediato sustituye a ésta: "una imagen en el lugar de la cosa". Asimismo, tenemos la indicación del carácter convencional del símbolo, cuya comprensión está supeditada a un acuerdo inconsciente.

El horizonte de estas reflexiones, las cuestiones que trata de resolver, tanto como el punto de vista general y la manera particular de plantear el problema remiten en todo momento a Schopenhauer ${ }^{13}$, a su manera de entender los conceptos como

\footnotetext{
12 En este sentido se encuentra también menciones explícita en: Niezsche, eKGWB/NF-1869, 3[32], eKGWB/NF-1870, 5[33,123], 8[78]

${ }^{13}$ Este había señalado que una de las diferencias esenciales entre su filosofía y la de Kant se hacía comprensible a la luz de la distinción entre "conocimiento reflexivo" y "conocimiento intuitivo": mientras Kant "parte del conocimiento mediato y reflexivo" -afirma- su método partía del conocimiento "inmediato, intuitivo". A tal divergencia en el punto de partida corresponde una diferencia en la concepción de la filosofía: mientras ésta sería para Kant una "ciencia de conceptos",
} 
Crítica al discurso representativista como desenmascaramiento de la metafísica.

representaciones de representaciones.

Schopenhauer, recriminándole a Kant el no haberse ocupado expresamente de clarificar cuál es la relación de la reflexión con el conocimiento intuitivo, de qué manera aquella reproduce y representa a éste, se posiciona y distribuye con toda precisión los papeles que corresponden a la reflexión y a la intuición en el proceso de conocimiento:

la reflexión no es al conocimiento intuitivo como el reflejo de un objeto en el agua, sino más bien como la sombra de un cuerpo es a este mismo cuerpo, del que reproduce solamente el contorno exterior, pero también unifica lo diverso en la forma y presenta el mayor número de diferencias en un mismo perfil; de manera que partiendo de ella no se pueden reconstruir de modo completo y seguro las formas de las cosas (Schopenhauer, WWV I, SW, I, pp. 611-612)

La acción pauperizante de la reflexión sobre la intuición acentúa el carácter esquematizante y simplificador de la primera, que opera a partir de una selección de elementos de la segunda, de este modo, la reflexión es caracterizada como una copia cuya fidelidad al original es parcial y sesgada:

la reflexión es necesariamente una copia, una reproducción del arquetípico mundo de la intuición, pero una copia de naturaleza totalmente propia, en un material completamente heterogéneo. Por eso se puede llamar a los conceptos, de manera muy apropiada, representaciones de representaciones (Schopenhauer, WWV I, §9; SW I, p.79).

La naturaleza del conocimiento exige que se parta de lo concreto de la representación intuitiva y se proceda alejándose de ésta hacia la abstracción creciente. Sin embargo, no debe soslayarse aquí el hecho, enfáticamente subrayado por Schopenhauer, de que las representaciones intuitivas son ya re-presentaciones, esto es, construcciones debidas a la actividad del intelecto, de ningún modo una impronta en nosotros de algo en sí "exterior", según se ha entendido que es la sensación. Sin la labor del intelecto, la solo sensación- mera modificación de los órganos sensibles corporales que, como tal, "no traspasa nuestra envoltura cutánea" ni puede contener

para Schopenhauer sería una "ciencia en conceptos", derivada del conocimiento intuitivo. (Schopenhauer WWV I, SW. I, p.611) 
nada que resida fuera de dicha envoltura no pasaría de ser el contenido en bruto de actos particulares de conciencia, patrimonio privado sin ningún significado objetivo.

En consecuencia, las representaciones intuitivas, siendo la base del conocimiento, no rebasan en absoluto el ámbito de la representación, sino que son ya un grado del mismo. De ahí que Schopenhauer, partiendo de que el mundo de la experiencia es una manifestación de la cosa en sí, (la Voluntad) lo equiparase a una vasta criptografía o "escritura secreta" que es menester descifrar, lo que parece resonar en los términos "símbolo" y "jeroglífico" en el fragmento antes citado de Nietzsche.

Una idea que el joven Nietzsche sintetiza de un modo más claro y directo en un extenso fragmento póstumo (primeras semanas de 1871) destinado a la elaboración de Die Geburt der Tragödie aus dem Geiste der Musik. En él leemos:

En la multiplicidad de las lenguas se revela inmediatamente el hecho de que palabra y cosa no coinciden ni completamente ni necesariamente, sino que la palabra es un símbolo. Pero ¿qué es lo que simboliza la palabra? Pues, por cierto, nada más que representaciones, sean éstas conscientes o, como sucede la mayoría de las veces, inconscientes: pues ¿cómo podría corresponder una palabra-símbolo con esa esencia interior, de la que nosotros mismo y el mundo somos imágenes? Ese núcleo sólo lo conocemos en forma de representaciones, y únicamente nos es familiar en sus expresiones simbólicas: fuera de esto no hay ningún puente directo que nos conduzca hasta el mismo (Nietzsche, eKGWB/NF-1871,12 [1]).

\section{El carácter ilusorio de las representaciones, la cultura, la vida.}

Este carácter simbólico-imaginativo que empieza a descubrir en el concepto, nos remite a otro elemento clave para la comprensión de la evolución y desarrollo del pensamiento del joven Nietzsche: el de ilusión (Wahn). Una idea que le permitirá ir descubriendo el carácter arbitrario, superficial y antropomórfico de las operaciones del intelecto y que se revela como herencia inmediata de las lecturas que hacemos referencias.

Nietzsche alcanzó a vislumbrar que tanto el conocimiento como los diversos 
Crítica al discurso representativista como desenmascaramiento de la metafísica.

aspectos de la vida en general no eran posibles sin concepciones fantasmagóricas, míticas, falsas o imaginarias. Ideas que lejos de corresponder o manifestar una adequatio intellectus et rei, eran, por el contrario, inventadas, erróneas e inconscientemente empleadas por el hombre en bien de la vida y el conocimiento. Una perspectiva de la ficción que estudiosos del tema como Hans Vainhinger adscriben a la herencia de su maestro Schopenahuer, y probablemente a R. Wagner en su doctrina de la "alucinación", señalando a su vez, que el uso consciente de tales ilusiones en la ciencia y la especulación filosófica, procede directamente de las páginas de la Geschichte des Materialismus en las que Lange formula su concepción de la metafísica como forma justificada de poesía. En consecuencia, con esto, ha sostenido que "en lo que respecta a la llusión Nietzsche debe ser definitivamente considerado como un discípulo y sucesor de Lange" (Vainhinger, 1996, p.43) ${ }^{14}$

Recordemos que, en Schopenhauer, la conciencia y el conocimiento (los procesos conscientes del conocimiento) están supeditados a la actividad ciega y sin fines de la voluntad. Todo el ámbito del conocimiento es derivado y la vida de los hombres, en la medida en que se ajusta a las leyes del mundo como representación, es una vida gobernada por la ilusión (Wahn).

Una caracterización exhaustiva del carácter y alcance de esta ilusión la encontramos en Die Welt als Wille und Vorstellung, en las páginas en que Schopenhauer se ocupa del amor sexual:

...la naturaleza sólo cuenta para realizar sus fines con el medio de infundir al individuo una ilusión que le haga considerar como su propio interés el de la especie, de modo que ponga al servicio de ésta la actividad que cree emplear para la consecución de su propio bien (Schopenhauer, WWV IV, cap. XLIV, p.920).

\footnotetext{
${ }^{14}$ En este sentido agrega Vaihinger (1996) "Nietzsche, como Lange, subraya la gran significación de las "apariencias" en los diferentes campos de la ciencia y la vida, y, lo mismo que él, señala la fundamental y vastísima función de la "invención" y la "falsificación", como también la influencia falsificadora de la "creación" poética, y con ello el valor y justificación del "mito" -no sólo en religión-. A igual que Lange, mantiene que, frente al mundo del "cambiante" y "evanescente" devenir, se establece, en interés de la comprensión y la satisfacción estética de la "fantasía", un mundo del "ser", en el que todo aparece "redondo" y completo; que de esta forma surge una antítesis, un "conflicto" entre "conocimiento" y "arte", "ciencia" y "sabiduría", que sólo se resuelve reconociendo que este mundo "inventado" es un "mito" justificado e "indispensable"; de lo que finalmente se sigue que "falso" y "verdadero" son conceptos relativos" (p. 44)
} 
De esta manera, la voluntad individual, el instinto sexual, que es mera voluntad de vivir (necesidad subjetiva), es en realidad Voluntad de la especie, que mediante la máscara de la admiración objetiva engaña a la conciencia para conseguir su fin, que no es otro que la reproducción de la especie.

En efecto, el concepto de ilusión en Nietzsche -como muchos aspectos de su pensamiento en este período- caminará por las veredas marcadas por Schopenhauer; a través de un camino lleno de tentativas, esbozos y reformulaciones que podemos ir rastreando tanto en su obra publicada como en los apuntes, notas y ensayos que guarda celosamente para él. Especulaciones que le permitirán ir consolidando su propia perspectiva del problema alcanzando su punto decisivo en Über Wahrheit und Lüge im aussermoralischen Sinne, donde la desviación consciente de la realidad que se encuentra en el mito, el arte, la metáfora, se definirán como "mentir en sentido extramoral" ${ }^{\prime 15}$.

En su primer obra Die Geburt der Tragödie aus dem Geist der Musik, y en estrecha relación con Schopenhauer, Nietzsche asigna un papel central al concepto de ilusión (Wahn) en la medida que, si la vida de los hombres es posible, lejos de deberse a una relación de correspondencia y armonía con el "fondo de las cosas" (armonía práctica fundada en una relación de verdad como correspondencia) se debe a su capacidad artística, a su ser creador de ilusiones (Nietzsche, eKGWB/GT -1)

De este modo, Nietzsche describe dos instintos artísticos-naturales fundamentales (lo apolíneo y lo dionisíaco), configuradores ambos de la cultura griega cuya concreción más lograda y definitiva se da en la escena trágica. Según Nietzsche el dominio de los instintos apolíneos, que no sólo abarca las artes sino asimismo el sueño, se corresponde con el ámbito de la gran ilusión -el "velo de Maya"- que oculta a los ojos de los hombres la verdad aterradora del fondo dionisíaco de las cosas. Esta verdad terrible es la del universal devenir que despoja de sentido a la existencia al no hacer de ella más que un efímero fruto del azar. Lo que encontramos en las palabras de Sileno interrogado por Midas:

\footnotetext{
${ }^{15}$ En este sentido expresa Vaihinger (1996) "La adhesión intencional a la ilusión, aunque se tenga consciencia de su naturaleza, es una forma de "mentira en un sentido extramoral"; y "mentir" es simplemente el estímulo consciente e intencional de la ilusión" (P.46).
} 
Estirpe miserable de un día, hijos del azar y de la fatiga, ¿por qué me fuerzas a decirte lo que para ti sería muy ventajoso no oír? Lo mejor de todo es totalmente inalcanzable para ti: no haber nacido, no ser, ser nada. Y lo mejor en segundo lugar es para ti - morir pronto (Nietzsche, eKGWB/GT -3).

El famoso monólogo de Hamlet, (Shakespeare, 1967, p. 1346) tiene el mismo

tono. La apariencia, la ilusión, es el presupuesto necesario para el arte, así como para la vida. El arte griego se presenta no como sometimiento o consuelo, sino como atenuación y disimulación del "fondo de las cosas", como un freno a la lucidez desilusionada, a la descarnada crítica que pudiera llevar a la inmovilización de las potencias creadoras. ${ }^{16}$

El arte, la ficción mítica, es la creación consciente de una ilusión estética que hace que merezca la pena la existencia y que para el hombre superior ${ }^{17}$ es, debe ser, una ilusión consciente.

Estas reflexiones sobre estética griega, esta conciliación entre arte y vida, podría ser quizás los primeros pasos (el telón de fondo) de un proyecto que comienza resaltando la visión del "arte desde la óptica de la vida" para postular desde aquí la necesidad de una perspectiva mayor: la de "ver la ciencia desde la óptica del arte y este

\footnotetext{
${ }^{16}$ Comenta Nietzsche (eKGWB/GT-7): “En este sentido el hombre dionisíaco se parece a Hamlet: ambos han visto una vez verdaderamente la esencia de las cosas, ambos han conocido, y sienten náusea de obrar; puesto que su acción no puede modificar en nada la esencia eterna de las cosas, sienten que es ridículo o afrentoso el que se les exija volver a ajustar el mundo que se ha salido de quicio. El conocimiento mata el obrar, para obrar es preciso hallarse envuelto por el velo de la ilusión [...] es el conocimiento verdadero, es la mirada que ha penetrado en la horrenda verdad lo que pesa más que todos los motivos que incitan a obrar, tanto en Hamlet como en el hombre dionisíaco. Ahora ningún consuelo produce ya efecto, el anhelo va más allá de un mundo después de la muerte, incluso más allá de los dioses, la existencia es negada, junto con su resplandeciente reflejo en los dioses o en un más allá inmortal. Consciente de la verdad intuida, ahora el hombre ve en todas partes únicamente lo espantoso o absurdo del ser, ahora comprende el simbolismo del destino de Ofelia, ahora reconoce la sabiduría de Sileno, dios de los bosques: siente náusea". Y en otro momento afirma Nietzsche (eKGWB/GT-16): "Aquí, en este peligro supremo de la voluntad, aproxímase a él el arte, como un mago que salva y que cura: únicamente él es capaz de retorcer esos pensamientos de náusea sobre lo espantoso o absurdo de la existencia convirtiéndolos en representaciones con las que se puede vivir".

${ }^{17}$ En este sentido Nietzsche a finales de 1870 ya expresaba (eKGWB/NF-1870, 6[3]): "El genio tiene la fuerza de colgarse a sus espaldas el mundo con una nueva red de ilusiones. (...) El conocimiento trágico es, también frente a la esencia de lo Uno primordial, sólo una representación, una imagen, una ilusión. (...) El genio actúa, por lo general, arrojando una nueva red de ilusiones sobre una masa, dentro de la cual ella puede vivir."
} 
desde la vida"18. El concepto de ilusión (Wahn) le permite a Nietzsche ir ensayando sus primeras formulaciones de la "fuerza artística", de la capacidad artística implícitas en el proceso de conocimiento, a la vez que auscultar las condiciones de posibilidades de una cultura que trasforme en sentido positivo al europeo contemporáneo.

El conocimiento tiene un fin estético cuyos instrumentos son las imágenes ilusorias (Nietzsche, eKGWB/NF-1870, 7[174]). Un instrumento desde donde la Voluntad traza sus fines a través del individuo y quizás en contra de su conciencia (Nietzsche, eKGWB/NF-1870, 7 [121]).

Hemos de recordar aquí, que el intelecto es sólo un órgano de la voluntad y tiende en toda su actividad, con una codicia necesaria, hacia la existencia, y que respecto a su fin se trata solamente de distintas formas de existencia, pero nunca de la pregunta por el ser o no-ser. El intelecto nunca tiene como fin la nada y tampoco un conocimiento absoluto, puesto que éste sería un no-ser respecto al ser. Favorecer a la vida -seducir a la vida es, por consiguiente, el propósito que subyace a todo conocimiento, el elemento ilógico, el cual como padre de todo conocimiento, define también los límites del mismo (Nietzsche, eKGWB/NF-1870, 7[125])

En las representaciones ilusorias, reconocemos la intención de la voluntad, la representación es entonces un producto de la voluntad (Nietzsche, eKGWB/NF-1870, 5[80]). No hay conocimiento puro y desinteresado, sino que "El mundo de las representaciones es el medio de mantenernos en el mundo de la acción y constreñirnos a actuar al servicio del instinto. La representación es un motivo para la acción: mientras que ella no toca la esencia de la acción" (Nietzsche, eKGWB/NF-1870, $5[77])$.

Nuestro intelecto nunca nos conduce más allá del conocimiento consciente, nunca traspasa la esfera del fenómeno, "ahora la individuatio se basa en la representación: si ésta es ahora engaño, si es solamente aparente, para ayudar a la voluntad a obrar -la voluntad actúa- para la unidad, en una inaudita pluralidad" (Nietzsche, eKGWB/NF-1870, 5[79]).

\footnotetext{
${ }^{18}$ En una carta dirigida a su amigo E. Rohde del 15 de febrero de 1870 (eKGWB/BVN-1870, 58) confiesa sus inquietudes del siguiente modo: "Ahora, dentro de mí, ciencia, arte y filosofía crecen juntos de tal forma que alguna vez, ciertamente, pariré centauros"
} 
Crítica al discurso representativista como desenmascaramiento de la metafísica.

En el mismo sentido Nietzsche concibe el mundo en general como un organismo inmenso que se engendra a sí mismo y se conserva mediante las representaciones creadas por el instinto colectivo. De este modo la voluntad ofrece al individuo imágenes fantasmagóricas, o "motivos" para la acción de carácter cada vez más generales, abstractos y espirituales, como por ej. la meta de la "humanidad" que, disueltos como tales en el andamiaje cultural, el sujeto asume como propios, convirtiéndose en siervos de la voluntad (Nietzsche, eKGWB/NF-1870, 5[77], 5[91]).

El "mecanismo de la representación” (Der Vorstellungsmechanismus) como mecanismo de alucinación tiene a su vez una expresión mayor en estamentos como la religión, la educación o el Estado, donde un número ilimitado de representaciones, de ilusiones pretextadas, permiten la perpetuación de la especie.

De este modo, por ejemplo, el impulso político, que tiende a conservar la cultura, será el medio por el cual la Voluntad instrumente al individuo particular quien en busca de su propia seguridad en el Estado se convertirá en un servidor feliz de objetivos más altos de los que alcanza a percibir (Nietzsche, eKGWB/NF-1870, 7 [23] , eKGWB/NF-1871, 10 [1]).

Así, la voluntad de existir utilizará la filosofía como objetivo de una forma superior de existencia (Nietzsche, eKGWB/NF-1872, 19[45]) donde se reconoce consciente y placenteramente la necesidad de ilusiones. Es decir, de asumir conscientemente ficciones (no-verdades) por verdades. El filósofo y el artista ocupan el lugar del mito que desaparece (Nietzsche, eKGWB/NF-1872, 19[17]). No es ya sólo la ilusión artística, el "velo artístico", aquella cuya necesidad para la vida es reconocida: ahora el círculo de ilusiones reconocido como necesario y entendido conscientemente es ampliado no sólo al terreno de la cultura sino también al de nuestro conocimiento. Este operar de nuestro intelecto con símbolos conscientes, con imágenes inadecuadas de la realidad, nos advierte que "es absurdo afirmar la conexión necesaria entre voluntad y representación: la representación se revela como un mecanismo engañoso, que no necesitamos presuponer en la esencia de las cosas" (Nietzsche, eKGWB/NF$1870,5[80])$. 
A modo de síntesis:

Como hemos tratado de explicitar, desde el mismo inicio de sus indagaciones, Nietzsche comprende el ejercicio filosófico como una tarea de lectura y relectura. De críticas y autocríticas constantes que lo llevan a indagar en torno a diferentes propuestas teóricas de su época y a emprender una "investigación genética" de las aeternae veritates presentadas por la tradición filosófica.

La crítica a la filosofía de Schopenhauer y Kant desde la perspectiva de autores como Lange o Hartmann, permiten al joven pensador afianzarse en la convicción de que cualquier crítica a la filosofía, a la cultura en general, debería abandonar toda valoración supra-histórica y anclarse en el "hilo conductor del cuerpo", en la historia.

Sus preocupaciones por establecer el trasfondo inconsciente e instintivo de todo conocimiento, el valor artísitico-illusorio de la verdad, se presentan como la cartografía de los que inmediatamente después -luego de su lectura de Die Sprache als Kunst de G. Gerber- reformulará desde su concepción retórica del lenguaje.

Este entramado de relaciones, tensiones y experimentaciones que Nietzsche realiza a partir de su universo de lecturas, le permiten ir adquiriendo de manera paulatina las herramientas para su crítica a lo que él mismo denomina "idealismo filosófico" o "pensamiento metafísico". Desenmascarar las ambiciones del optimismo filosófico que instauró en la cultura occidental una fe desmedida en la razón, la duplicidad de mundos y la posibilidad de un conocimiento puro y objetivo. 


\section{Bibliografía}

Barrios Casares, M. (2002) Voluntad de lo trágico. El concepto nietzscheano de voluntad a partir de El Nacimiento de la Tragedia. Madrid: Biblioteca Nueva.

Conill, J. (1997) El poder de la mentira. Nietzsche y la política de la transvaloración. Madrid: Tecnos.

Crawford, C. (1988) The Beginning of Nietzsche's Theory fo Language. Berlín: Gruyter.

Curt, P. (1981) Friedrich Nietzsche Vol.I. Infancia y Juventud. Madrid: Alianza.

De Santiago Guervós L. (2004) Arte y poder. Aproximaciones a la estética nietzscheana. Madrid. Trotta.

Gentilli, C. (2010) Kants kindischer Anthropomorphismus. Nietzsches Kritik der objektiven Teleologie. Nietzsche-Studien, 39, 100-119.

Gerratana, F. (1988) Der Wahn jenseit des Menschen, Zur frühen Eduard von Hartmann-Rezeption Nietzsche. Nietzsche Studien, 17, 391-433.

Göde, G. (1999) Traditionslinien des Unbewussten. Schopenhauer, N., Freud, Tübingen: Diskord.

Halévy, D. (1943). La vida de Federico Nietzsche. Bs. As.: Emecé.

Hartmann, E. (1869) Philosophie des Unbewussten. Berlín, 1869

Lange, F. (1974) Geschichte des Materialismus und Kritik seiner Bedeutung in der Gegenwart. Frankfurt: Suhrkamp Verlag.

Löw, R. (1984) Nietzsche sophist und Erzieher. Philosophische Untersuchungen zum systematischen Ort von F. Nietzsches Denken. Weinheim: Acta Humaniora.

Mittasch, A. (1952) Nietzsche als Naturphilosoph. Stuttgart: Kröner,

Nietzsche F. (1967 y ss.) Werke, Kritische Gesamtausgabe, herausgegeben von G. Colli und M. Montinari, Berlín, de Gruyter, (edición digital corregida: http://www.nietzschesource.org/).

Safranski, R. (2001). Nietzsche. Biografía de su pensamiento. Barcelona: Tusquets.

Salaquarda J. (1978) Nietzsche und Lange. en Nietzsche Studien 7, 236-253.

Salaquarda J. (1992) Nietzsche e Lange. En: G. Campioni, y A. Venturelli, (Eds.), La "Biblioteca ideale" di Nietzsche, (pp. 19-43) y Napoli, Guida

Salaquarda, J. (1979) Der Standpunkt des Ideals bei Lange und Nietzscheen Studi Tedeschi,, 21, 1 Napoli, Guida 


\section{Sebastián Bisang y Fernando Fava}

Sánchez, S. (1999) El problema del conocimiento en el joven Nietzsche. Los póstumos del período 1867-1873. Córdoba: Universitas.

Schopenhauer, A. (2009) Sämtliche Werke. Herausgegeben von Julius Frauenstät. Fünfter Band: Parerga una Paralipomena. Kleine philosophische Schriften. Erster Band (P. López de Santamaría Trad.) Madrid. Trotta (Primera edición 1874)

Shakespeare, W. (1967) Obras Completas. (L. Antana Marin Trad.) Madrid: Aguilar.

Stack, George J. (1983) Lange and Nietzsche, Walter. Berlin-New York: Gruyter.

Vaihinger, H. (1996) La voluntad de ilusión en Nietzsche. Madrid. Tecnos.

Wegener, M. (2005) Unbewußt.das Unbewußte. En Bark,K. y Fontius, M., Schlenstedt D u. a. (ed.), Historisches Wörterbuch ästhetischer Grundbegriffe, (pp. 202-240) vol. 6. Stuttgart, Weimar. 